\title{
The Morphology, Structure and Composition of Microarc Oxidation (MAO) Ceramic Coating in Ca-P Electrolyte with Complexing Agent EDTMPS and Interpretation Hypothesis of MAO Process
}

\author{
Maolin Shi, Hongyou Li \\ College of mechanical engineering and automation, Huaqiao University, \\ 668 Jimei rev., Xiamen, Fujian, China, e-mail: shl5985336@126.com
}

\begin{abstract}
A new MAO ceramic coating was fabricated in Ca-P electrolyte with a eco-friendly easily degradable complexing agent EDTMPS instead of current common EDTA-2Na. A 3-Dimensional video microscope and SEM were utilized to observe surface and cross-section morphology, and statistics of coating surface were measured by image software ImageJx 2.0. Elements and phases compositions were detected by EDS and XRD respectively, and XPS was further undertaken to provide more information about the components of the two complexing agents MAO coatings surfaces. The results indicate that the elements and phases composition of the two MAO ceramic coatings are similar. The surface morphologies show the difference, which is a result of more melting metal during the treatment in EDTMPS electrolyte compared with EDTA-2Na. The results of recent studies of discharge and discharge plasma in low temperature liquid and thermodynamics were introduced into the establishment of MAO process models which was divided into three parts: cusp area, even area and sunk area. Active particles, $\mathrm{O}_{2}$, free radical $\cdot \mathrm{OH}$, free radical $\mathrm{H}_{2} \mathrm{O}_{2}$, free radical $\cdot \mathrm{H}$ brought by discharge and discharge plasma play a significant effect on the phase transformation, electrolyte elements diffusion from electrolyte to coating and substrate and chemical reactions. Crater shape of surface morphology is mainly attributed to the sharply increasing pressure with the decreasing of temperature. Finally, a interpretation of MAO process based on the theory of thermodynamics, and discharge plasma in low temperature liquid was developed.
\end{abstract}

Keywords: micro-arc oxidation, Ti alloy, complexing agent, discharge in low temperature liquid.

УДК 539.975

\section{INTRODUCTION}

Microarc oxidation (MAO), also called plasma electrolytic oxidation (PEO) [1-3], is a costeffective and environmentally friendly method of producing thick, hard and bioactive ceramic coatings with excellent corrosion resistance, wear resistance and bioactivity properties on light alloys especially on aluminum, magnesium and titanium [4-7]. The driving force for these developments is the straight forward process and the avoidance of costly equipment required for competing vacuum-based plasma technologies. The coating's microstructure and properties were got much more attention than the growth mechanisms of the MAO coating [8-15].

The formation mechanisms of the coating layer by MAO are complex due to the involvement of electro-, thermal-, and plasma-chemical reactions in the electrolyte [2-3]. Over the past decades, the effects of the process parameters on the characteristics of the MAO coatings on $\mathrm{Ti}$ and Ti-alloys have been investigated in a number of different studies. The chosen of $\mathrm{Ti}$ alloy substrate is also significant in the whole process of fabricating Ti-alloy implant through MAO. A new titanium alloy TB9 has recently been developed as a struc- tural implant biomaterial. This alloy is characterized not only by a lower elastic modulus which could reduce the implant-bone interface stress but also by relatively non-toxic elements existing in its composition. Some of these publications deal with the influence of the Ca-P electrolyte, which is built on an alkaline solution with additions of phosphates and calcium. However, calcium ions are easy to generate precipitation in alkaline electrolyte. The current common complexing agent EDTA-2Na is introduced to prevent the reactions between calcium ions and hydroxyls [9], [13]. That complexing agent is environmentally unfriendly, whose massive waste electrolyte would bring a serious of environmental pollution problems after industrial application. In recent years, a new complexing agent EDTMPS (ethylene diamine tetra (methylene phosphonic acid) sodium) belonging to organic phosphonic salts has been developed with various advantages, such as non-toxicity, pollution-free, durothermic and better complexing ability [20]. Thus, it is preferable to apply EDTMPS into the MAO electrolyte instead of EDTA-2Na. There are studies in the literature in which the effect of current mode and current density, the chemical composition of the substrate materials, the microstructure an the properties of the MAO

(c) Maolin Shi, Hongyou Li, Электронная обработка материалов, 2016, 52(1), 31-41. 
coatings has been investigated, and many authors have concentrated on the study of discharge and discharge plasma in lower temperature liquid which have significant influence on the MAO process [14-16], [18], [21].

In this paper, the MAO $\mathrm{TiO}_{2}$-based ceramic coating containing $\mathrm{Ca}$ and $\mathrm{P}$ elements was fabricated in the electrolyte with new environmentally friendly complexing EDTMPS instead of EDTA-2Na, and the properties of this coating were investigated and compared with those of EDTA-2Na. Simultaneously, we use the recent studies' results of discharge and discharge plasma in lower temperature liquid to establish the interpretation of MAO microcosmic process.

\section{EXPERIMENTAL PROCEDURE}

\subsection{Materials and pre-treatment}

The titanium alloy TB9 in the experiments is with a chemical composition of Ti-3.5Al-8V-6Cr4Mo-4Zr (at.\%). The specimens, $15 \mathrm{~mm} \times 10 \mathrm{~mm} \times$ $0.5 \mathrm{~mm}$ in dimension, were ground with 600\#, 800\#, $1000 \#$ and 1200\# abrasive papers, and ultrasonically washed with distilled water followed by acetone, and dried for EDTA-2Na and EDTMPS MAO treatment respectively.

\subsection{Coating preparation}

The ceramic coatings were fabricated by MAO process on the Ti alloy samples. The electrolytes of alkaline were prepared from the solution of $\mathrm{Ca}\left(\mathrm{CH}_{3} \mathrm{COO}\right)_{2}, \mathrm{NaH}_{2} \mathrm{PO}_{4}, \mathrm{NaOH}, \quad \mathrm{EDT}-2 \mathrm{Na}$ and EDTMPS in distilled water respectively. The concentrations of electrolyte components were determined according to other references as shown in Table 1 [13], [18]. A home-made microarc oxidation device provided the voltage waveforms, and the main pulse parameters, such as pulse duration, voltage amplitude and time were adjusted independently. In the experiments, the electrical parameters were fixed as follows: voltage $350 \mathrm{~V}$, frequency $200 \mathrm{~Hz}$ and time $120 \mathrm{~s}$.

\subsection{Properties of electrolyte}

The appearances of two different complexing agent electrolytes were observed by naked eyes and recorded by a digital camera of Samsung. The conductivities were measured to judge electrolyte dissolved complexation by a conductivity detector which is made in Shanghai China.

\subsection{Analysis and observation of coating morphology}

The surface and cross-section morphologies of the surface were observed by a FEI PHENOM scanning electron microscopy (SEM) (magnification: $2000 \times, 5800 \times$ and $7500 \times$ ). The images from SEM were analyzed to achieve porosity, pores density and the average size parameters of MAO coating porous structure by an image professional software ImageJx2.0. The thicknesses of MAO coatings were determined by TT230 coating and layer thickness measuring instrument. The results were the average values of ten different areas. The 3-D images and roughness's were taken by a HIROX video microscope with magnification $2500 \times$.

\subsection{Coating characterization}

The microstructure of the sample coating treated by MAO, was invested by X-ray diffraction (XRD) with a Philips X'pert diffractometer using $\mathrm{Cu} \mathrm{K \alpha}$ in the range of $10^{\circ}-100^{\circ}$, and the measurement were performed with a continuous scanning mode at a rate of $3^{\circ} / \mathrm{min}$ with an incident angle of $3^{\circ}$. The elements and their contents of ceramic coatings were measured by energy dispersive spectrometer (EDS) attached to PHENOM scanning electron microscopy. The valence states and energy levels of each main element were detected by a ThermoFisher SCIENTIFIC X-ray photoelectron spectroscopy (XPS).

\section{RESULTS}

The appearances of each electrolyte are shown in Figure 1. It can be found that the two electrolyte exerts lucency and the characteristics of complexing colloid similarly. The conductivities of the two electrolytes are given in Table 2. It can be found that calcium ions were complexed well after dissolved. And the property, complexing abilities of EDTMPS, is not weaker than that of EDTA-2Na. The conclusion is also reported in other authors' publications [20].

\subsection{Surface morphology and its statistics}

The SEM surface morphologies of MAO ceramic coatings coated on TB9 alloy are illustrated in Fig. 2, respectively. Typical MAO porous surface structures are formed on the two Ti alloy samples. Observations on the surface of the coated TB9 alloy indicated that the sizes of the pores are much smaller at the surface of EDTA-2Na than that of EDTMPS. The pores of EDTA-2Na coating surface are almost crater shapes, and the amount is more numerous compared with those of EDTMPS. It can be found that the pores of EDTMPS coating surface possesed inconformal shapes, and the sizes of several pores are almost ten times those of the other coating. The phenomenon can be attributed to the higher conductivity of EDTMPS. The EDTMPS electrolyte provide better electrical conditions, which allows 
Table 1. Concentrations of electrolyte components (Unit:mol/L)

\begin{tabular}{|c|c|c|c|c|}
\hline \multirow{2}{*}{$\begin{array}{c}\text { Complexing agent } \\
\text { EDTA-2Na }\end{array}$} & $\mathrm{NaOH}$ & $\mathrm{Ca}\left(\mathrm{CH}_{3} \mathrm{COO}\right)_{2}$ & $\mathrm{NaH}_{2} \mathrm{PO}_{4}$ & EDTA-2Na \\
\cline { 2 - 5 } & 0.05 & 0.060 & 0.036 & 0.060 \\
\hline $\begin{array}{c}\text { Complexing agent } \\
\text { EDTMPS }\end{array}$ & $\mathrm{NaOH}$ & $\mathrm{Ca}\left(\mathrm{CH}_{3} \mathrm{COO}\right)_{2}$ & $\mathrm{NaH}_{2} \mathrm{PO}_{4}$ & EDTMPS \\
\cline { 2 - 5 } & 0.05 & 0.060 & 0.036 & 0.030 \\
\hline
\end{tabular}

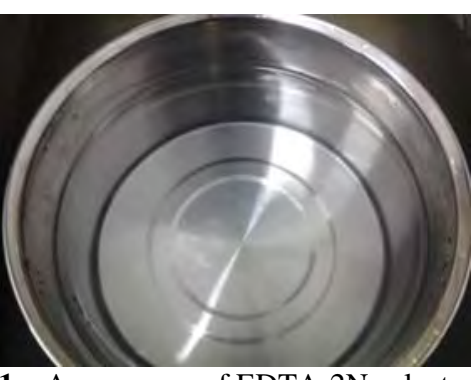

Fig. 1a. Appearance of EDTA-2Na electrolyte.

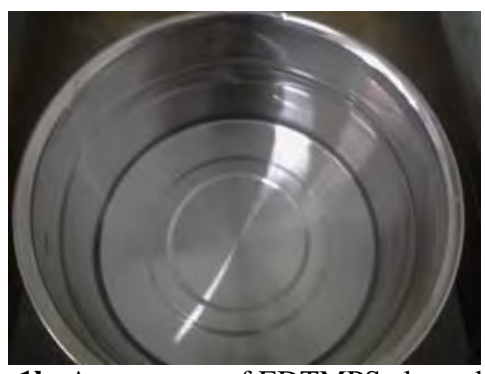

Fig. 1b. Appearance of EDTMPS electrolyte.

Table 2. Conductivities of different electrolytes

\begin{tabular}{|c|c|c|}
\hline Complexing agent & EDTA-2Na & EDTMPS \\
\hline Conductivity & $1249 \mathrm{us} / \mathrm{cm}$ & $1277 \mathrm{us} / \mathrm{cm}$ \\
\hline
\end{tabular}

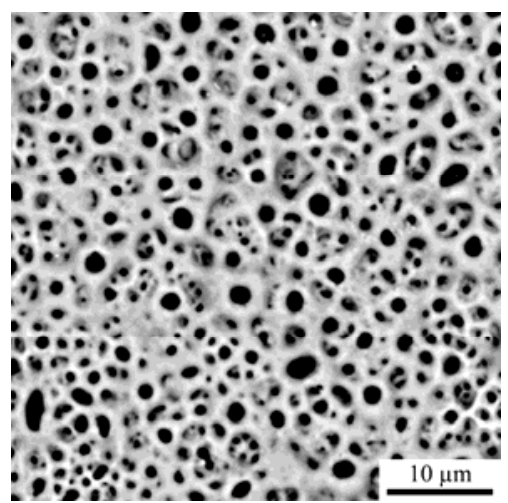

Fig. 2a. SEM image of coating surface morphology of EDTA-2Na.

easier inducement of discharge and produce more melting metal during the MAO process. Therefore, more melting metal coated on the sample surface. Thus, the connected non-uniform shape pores of EDTMPS coating could be due to the effect of melting metal coating effect. The uniformity of pores produced in EDTA-2Na solutions is attributed to the heritages of the discharge channels, which is also reported by others [14].

The 3-Dimensional images are shown in Figure 3. The 3-D morphology of EDTA-2Na is similar to chain of mountains. The 3-D morphology of EDTMPS is rugged, with several higher areas. The 3-D morphologies of the two coatings accord with the SEM images. The roughness results of EDTA-2Na and EDTMPS are given in Table 2, which are $1.14 \mu \mathrm{m}$ and $1.95 \mu \mathrm{m}$, respectively. The surface structure of coating prepared by using EDTA-2Na is far more uniform than that of EDTMPS, so that the roughness of EDTMPS is higher.

The porous structure is beneficial to the adhesion of biological tissue on titanium alloy implant. After threshold value processing of SEM images $(2000 \times)$ by digital image software, the statistics of each

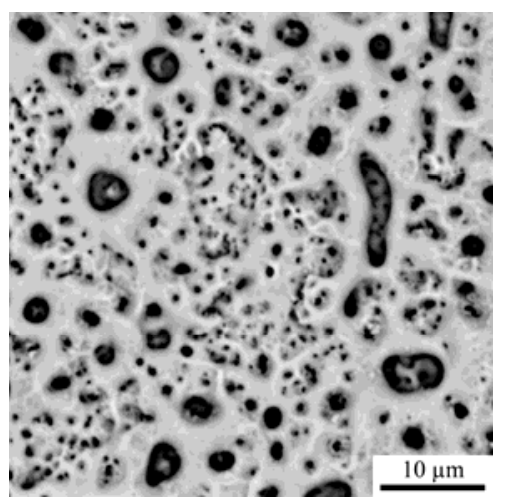

Fig. 2b. SEM image of coating surface morphology of EDTMPS.

MAO coating, porosity, pores density and the average radius parameters of pores, were measured by ImageJx 2.0. The results are shown in Table 3. It can be seen that porosities of EDTA-2Na and EDTMPS MAO coatings are similar (around 22.5\%) which meets the requirements of bioactivity (20\% 35\%) [22]. There are differences between pores density of EDTA-2Na MAO coating and that of EDTMPS MAO coating with $3625.8 / 10-8 \mathrm{~m}^{2}$ (EDTA-2Na) and 2518.5/10-8m ${ }^{2}$ (EDTMPS) respectively. The size parameters of the two complexing agents are 53.836 (EDTA-2Na) and 69.505 (EDTMPS). The statistics results can be attributed to more coating and condensation impact of more melting metal during MAO treatment in EDTMPS electrolyte. The more melting metal covered over initial small pores generated by discharges and generated new larger pores. Therefore, the pores density of EDTMPS with higher conductivity is lower, and the size of pores increase. Appropriate irregular "roughening" on implant surface can enhance the adhesion of bone issue significantly [22]. The amount of pores per unit area has important significance in the adhesive strength between $\mathrm{Ti}$ alloy and bone issue. Unfortu- 


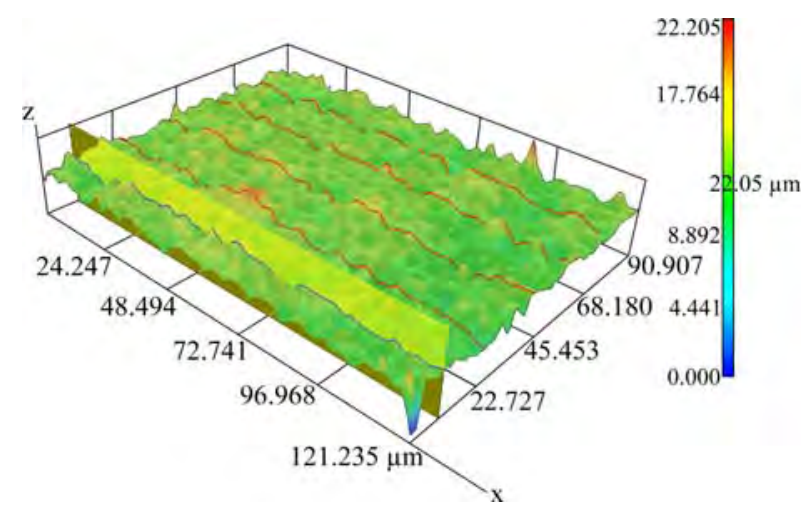

Fig. 3a. 3-D image of coating surface morphology of EDTA-2Na

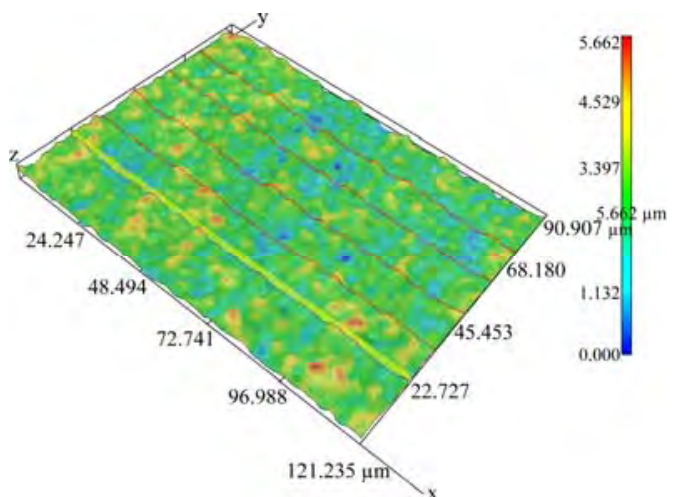

Fig. 3b. 3-D image of coating surface morphology of EDTMPS.

Table 3. Statistics of the morphologies of different electrolytes

\begin{tabular}{|c|c|c|c|}
\hline Complexing agent & Porosity & Pores density & The size parameters of pores \\
\hline EDTA-2Na & $23.2 / \%$ & $3625.8 / 10^{-8} \mathrm{~m}^{-2}$ & 53.836 \\
\hline EDTMPS & $21.9 / \%$ & $2518.5 / 10^{-8} \mathrm{~m}^{-2}$ & 69.505 \\
\hline
\end{tabular}

nately, studies and explorations of this aspect were rarely reported. How to obtain suitable pores density under the condition of certain porosity is an innovative new direction of improving biomedical performances of MAO ceramic coatings.

\subsection{Cross-section morphology and composition}

Figure 4 exhibits the cross section morphologies and corresponding element distribution across the section of MAO coatings fabricated in EDTA-2Na and EDTMPS electrolytes, respectively. It can be found that the each coating covered the substrate completely. However, EDTMPS coating exists distinct morphology characteristic with several pores in the coating. The phenomenon, more pores of EDTMPS coating, can be attributed to the influence of coating and condensation of excessive melting metal and the vestigial anode gas generated during the MAO treatment process compared with EDTA-2Na. These pores are also due to the heritage of anode gas which brought with great gas pressure (the details of the ratiocination are in the following part). The boundaries of each MAO coating between substrate and coating are not obvious. The innergrowth process of MAO treatment as the effect of thermochemistry, electrochemistry, diffusion and solid-state phase transformation is proved. The thicknesses of the two coatings are much thinner with around $4 \sim 5 \mu \mathrm{m}$. It can be concluded that the thickness under the power of voltage is thinner than that of current power according to other publications [2], which also could be concluded that current Joule heat energy might have a major effect on the growth of MAO coating.

The elements compositions of the cross-sections of EDTA-2Na and EDTMPS MAO coatings analyzed by EDS are shown in Fig. 4c,d. The analysis lines of MAO coating are from the surface to the interface between coating and substrate. From the EDS analysis of of EDTA-2Na MAO coating cross section as shown in Fig. 4c, the compositional distribution of $\mathrm{Ca}$ and $\mathrm{P}$ is similar, and the trends of $\mathrm{O}$ and $\mathrm{Ti}$ are similar. It can be found that oxygen dominates the whole composition with the maximum $64.6 \%$, followed by titanium, whose maximum makes up $30.6 \%$; then come calcium and phosphorus, and maximums are $15.7 \%$ and $12.7 \%$, respectively. The average percentages of each elements (O, Ti, P and $\mathrm{Ca}$ ) are 56.3\%, 25.1\%, 11.9\% and $8.7 \%$ (Fig. 4e). Calcium and phosphorus are introduced into the coating, which is the precondition of bio-implant and the sedimentation and growth of hydroxyapatite. The oxygen concentration on the interface is about $58 \%$, which is a result of the inner diffusion of anode oxygen gas to substrate during the MAO treatment. The elements composition of EDTMPS MAO coating in Fig. 4d shows similarity to that of EDTA-2Na MAO coating. Oxygen, calcium, phosphorus decrease from $66.8 \%, 12.8 \%$ and $11.3 \%$ to $43.1 \%, 1.3 \%$ and $2.1 \%$, respectively. Titanium increases from $23.1 \%$ to $45.8 \%$. The averages of elements are $51.7 \%$, $34.8 \%, 7.9 \%$ and $6.6 \%(\mathrm{O}, \mathrm{Ti}, \mathrm{P}$ and $\mathrm{Ca}$ ) (Fig. 4f). The concentrations of $\mathrm{O}, \mathrm{P}$ and $\mathrm{Ca}$ of the interface, $43.1 \%, 1.3 \%$ and $2.1 \%$, also indicate the element ions diffusion direction was into the substrate.

During the MAO process, metallic elements in the substrate diffuse outwards to form oxide layers. On the other hand, the $\mathrm{O}$ anions, in combination with the participation of $\mathrm{Ti}$ elements from the substrate, facilitates the formation of the oxide layers through discharge and discharge plasma. Ca cation and phosphate radical anions also reacted during the whole process. The results of cross section morphologies and EDS analysis indicate that the properties of EDTMPS coating are as better as those of EDTA-2Na. 


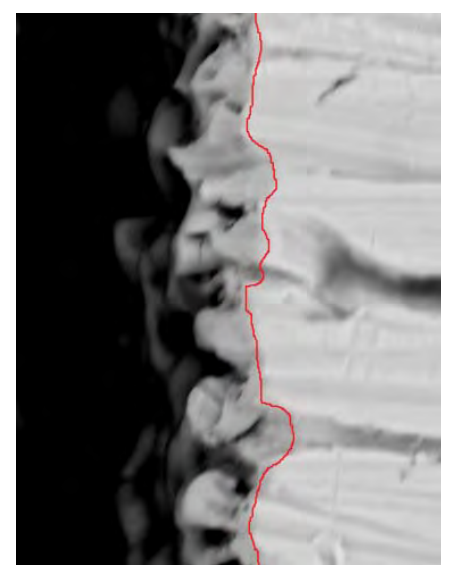

Fig. 4a. SEM image of coating cross-section morphology of EDTA-2Na

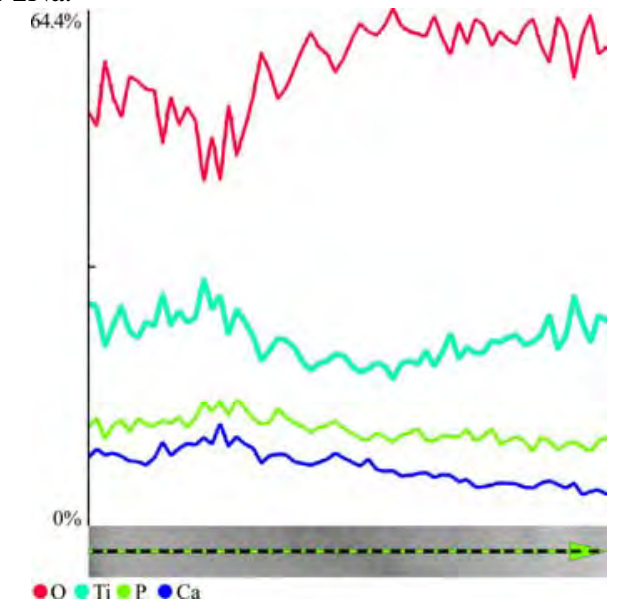

Fig. 4c. EDS analysis of coating cross-section elements composition of EDTA-2Na.

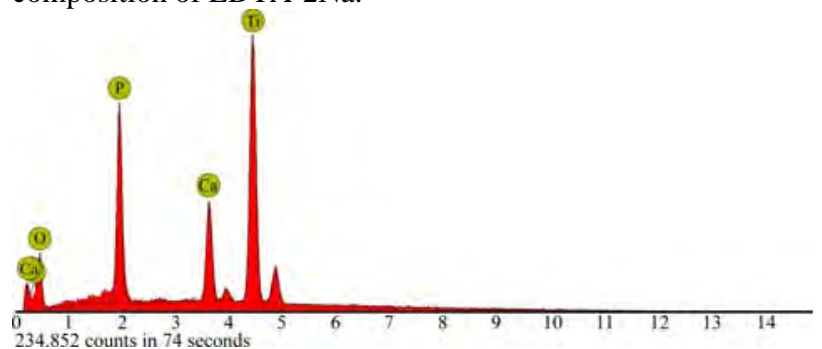

Fig. 4e. Average percentages of each element of coating crosssection of EDTA-2Na.

\section{3. $X R D$ analysis of $M A O$ coatings}

The XRD patterns of two different MAO ceramic coatings are shown in Figure 5. It can be found that rutile $\mathrm{TiO}_{2}$ is the highest peak in the X-ray patterns of EDTA-2Na and EDTMPS. There are various titanium oxide compounds (rutile $\mathrm{TiO}_{2}$, anatase $\mathrm{TiO}_{2}$, non-stoichiometric titanium oxide, and brookite $\mathrm{TiO}_{2}$ ) peaks in all the $\mathrm{X}$-ray patterns. It also proves that $\mathrm{Ca}$ and $\mathrm{P}$ elements penetrate into the coating and form particular compounds which are beneficial to the bioactivity of surface of $\mathrm{Ti}$ alloy. The XRD patterns of EDTA-2Na MAO coating reveal more and higher peaks of anatase $\mathrm{TiO}_{2}$. These factors of EDTMPS electrolyte, such as the higher conductivity and higher complexing capacity, are the main reasons, which bring higher temperature and more plasma which could propel the transformation

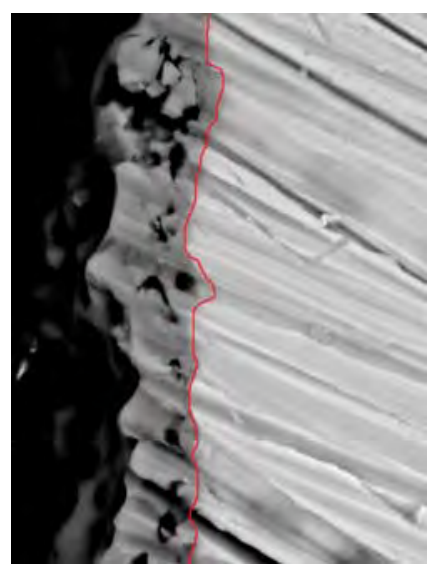

Fig. 4b. SEM image of coating cross-section morphology of EDTMPS.

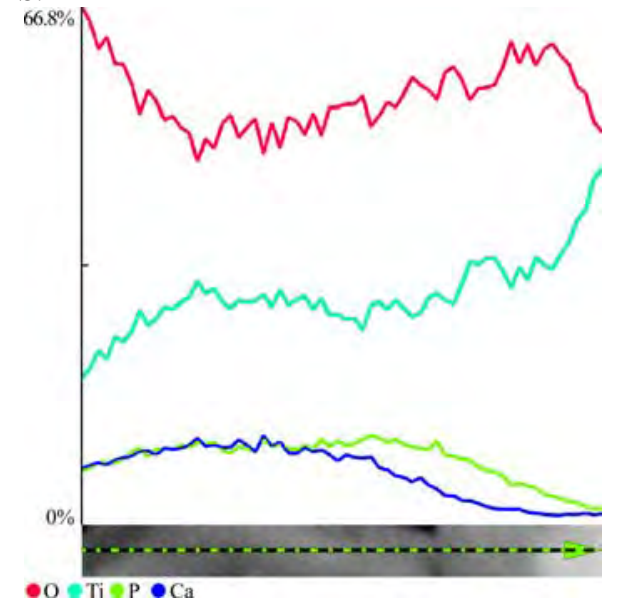

Fig. 4d. EDS analysis of coating cross-section elements composition of EDTMPS.

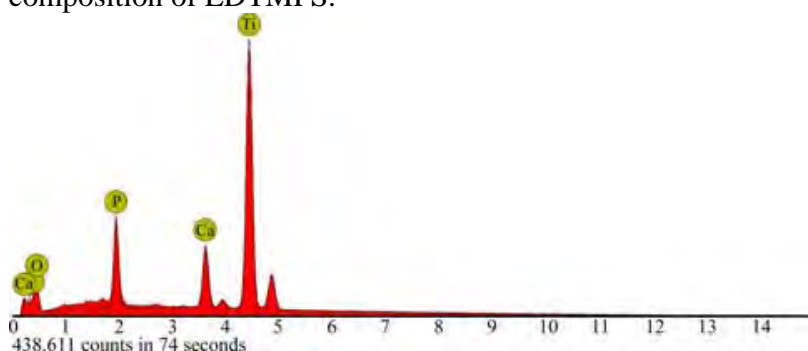

Fig. 4f. Average percentages of each element of coating crosssection of EDTMPS.

from anatase $\mathrm{TiO}_{2}$ to rutile $\mathrm{TiO}_{2}$. On the other hand, the chemical characteristics of EDTMPA which is the acid corresponding to EDTMPS is stable relatively, so that the $\mathrm{pH}$ of the reaction area would decrease with consumption of $\mathrm{OH}$-during the process. The acidic conditions is better for the transformation from anatase $\mathrm{TiO}_{2}$ to rutile $\mathrm{TiO}_{2}$. For the non-stoichiometric titanium oxide, it can be attributed to the aspect as follows: the length of single arc reaction process is so quick $(0.001 \sim 0.02 \mathrm{~s}$ reported by some papers) that the melt Ti alloy could not react with enough anodic oxide gas, which also means that the crystal lattice structure of new products has no enough time to adjust and left with crystal defects. Finally, the non-stoichiometric titanium oxide is generated. For the effect of $\mathrm{Ca}$ and $P$ salts on the composition, their effect could be neglected compared with $\mathrm{NaOH}$. According to the 
model we have studied based on the theory of electrochemistry and thermodynamics, the molar conductivity of electrolytic components plays important role in MAO. In the electrolyte used in this paper, the molar conductivity of $\mathrm{NaOH}$ is much higher than those of $\mathrm{Ca}\left(\mathrm{CH}_{3} \mathrm{COO}\right)_{2}$ and $\mathrm{NaH}_{2} \mathrm{PO}_{4}$. The fluctuation in the lower intensity of MAO coatings X-ray patterns is the influence of interference of substrate Ti alloy as the result of the thinness of MAO coatings and the amorphous calcium phosphorus compound. As shown in Fig. 5, although the phases composition of EDTMPS coating has few differences with that of EDTA-2Na coating, it can be found that the replacement of EDTA-2Na using EDTMPS is feasible as stated above.

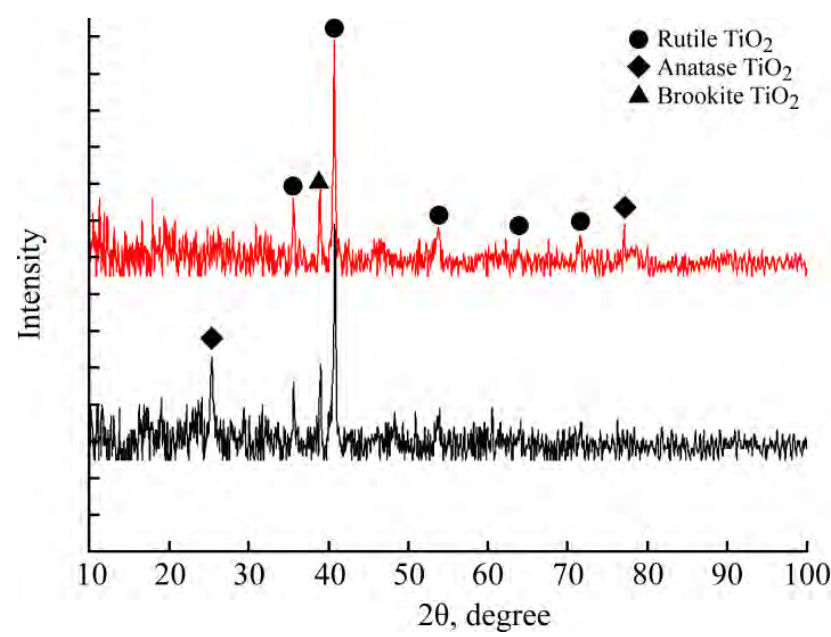

Fig. 5. XRD analysis of EDTA-2Na and EDTMPS MAO coatings.

\subsection{XPS analysis of MAO coatings}

XPS analysis was further undertaken to provide more information about the components of the two complexing agent MAO coating surfaces. As shown in Fig. 6, featured peaks of $\mathrm{Ti}, \mathrm{Ca}, \mathrm{P}$ and $\mathrm{O}$ were detected in XPS survey spectra. In the surface of MAO coatings, $\mathrm{Ti}$ is originated from substrate components, while $\mathrm{P}$ and $\mathrm{Ca}$ are introduced in the coating during MAO treatment. The two different MAO coatings fabricated in EDTA-2Na and ENTMPS electrolytes show similar featured peaks. The only Ti2p peaks of titanium element indicate that the nonstoichiometric compounds of titanium and oxide are due to the vacancies, replacement by phosphorus ions and oxygen ions and defects in $\mathrm{TiO}_{2}$-based original coating. However, the chemical compositions and molecular structures of the two MAO coatings cannot be determined accurately by the measurements above (EDS, XRD and XPS). It needs various advance modern measurements, such as transmission electron microscope (TEM), infrared spectroscopy (IR) and nuclear magnetic resonance spectroscopy (NMR), to gain detailed accurate information.
Through the measurements and analysis above, it can be found that the compositions and structures of the two MAO coatings of EDTA-2Na and EDTMPS are similar, which means that the replacement of EDTA-2Na by EDTMPS is feasible. However, properties experiments, such as implantation and sedimentation experiment in SBF, are still needed to be operated to gain more information about and test the bioactivity of EDTMPS MAO ceramic coating.

\section{HYPOTHESIS OF MAO PROCESS}

It is a consensus that the fabrication of MAO ceramic coating is the effects of thermo-, electroand plasma-chemistry [2]. Diffusions and physical chemical reactions prompt the entrance of elements, ions and molecules of the electrolyte into the coating and substrate [14]. However, the theories of MAO are not detailed and not able to explain specific process of MAO process. Most studies concerning about MAO majorly focus on the effect of the process parameters on the characteristics of the MAO coatings on $\mathrm{Ti}$ and Ti-alloys. The studies about the theories of MAO discharge reactions were rarely reported. In recent years, researchers studied discharge and discharge plasma in lower temperature liquid which contains microarc in MAO and got achievements which are significant and meaningful [21]. Discharge phenomenon in lower temperature liquid was studied more and grows up to be a hot new area in the past decades [23-28]. Unfortunately, the results of studies of discharge and discharge plasma in lower temperature liquid were rarely applied into the interpretation of MAO process and the analysis of the formation mechanism of the structure and characterization of MAO coatings. On the other hand, the description of MAO process and the interpretation of MAO reactions were macroscopical. The microcosmic description and interpretation of MAO was also rarely reported.

At the beginning of MAO, a thin oxidation insulating film is formed on the anode Ti alloy sample after energizing, and the generation of film is the prerequisite of MAO process. Since the capacitive properties of anode oxidation gas and the insulating film, the voltage is concentrated on the anode and the electrolyte. It needs to be claimed that the voltage focus and its higher value are also influenced by the crystal structure of Ti alloy. When Ti alloy is applied higher voltage, the ions near the surface would be induced and turn into dipoles. The reason is that those ions are not balanced because the incomplete crystal structure and potential field surrounding them. Then, the dipoles moved to the surface. The final result is that voltage increases to higher than the applied voltage value as a result of additive voltage of charge accumulation, and there is asymmetrical voltage distribution on the surface 


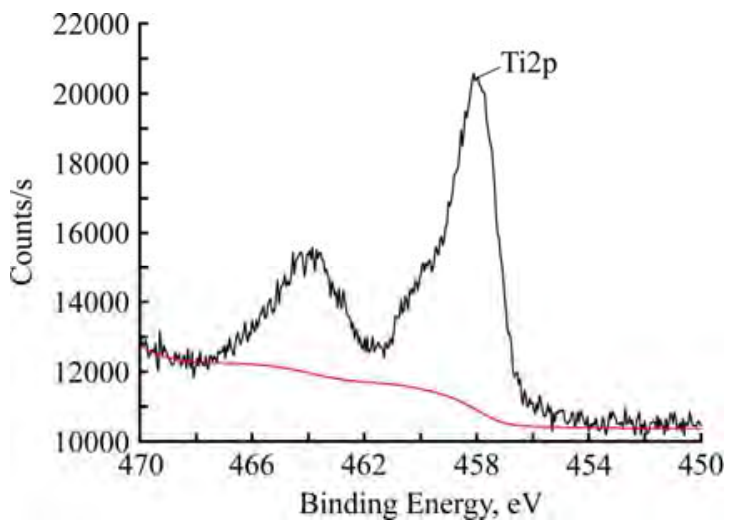

(a)

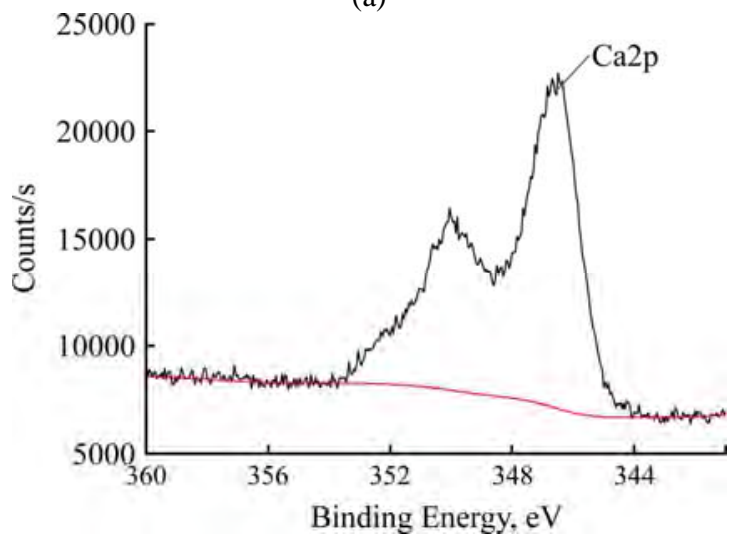

(c)

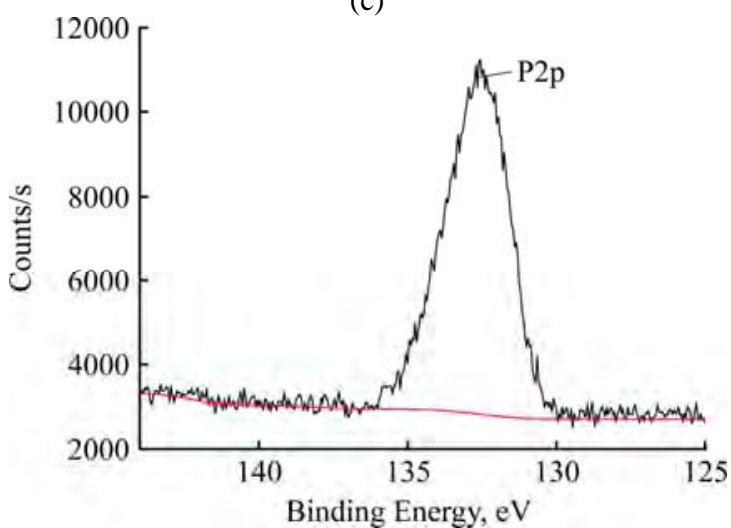

(e)

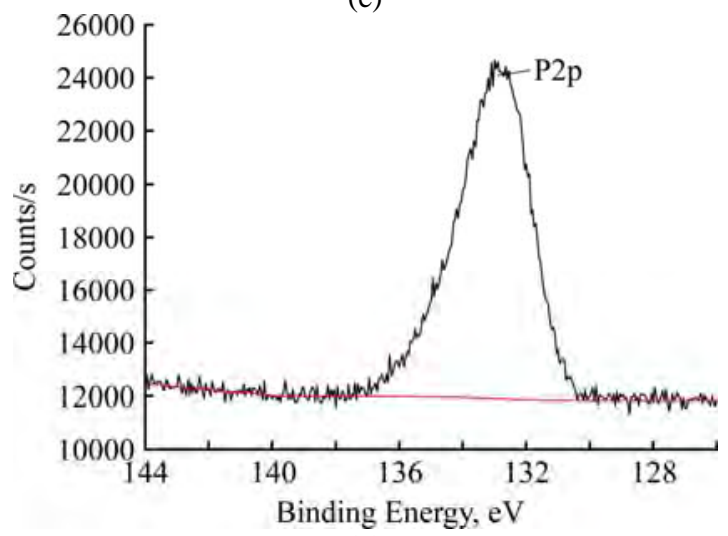

(g)

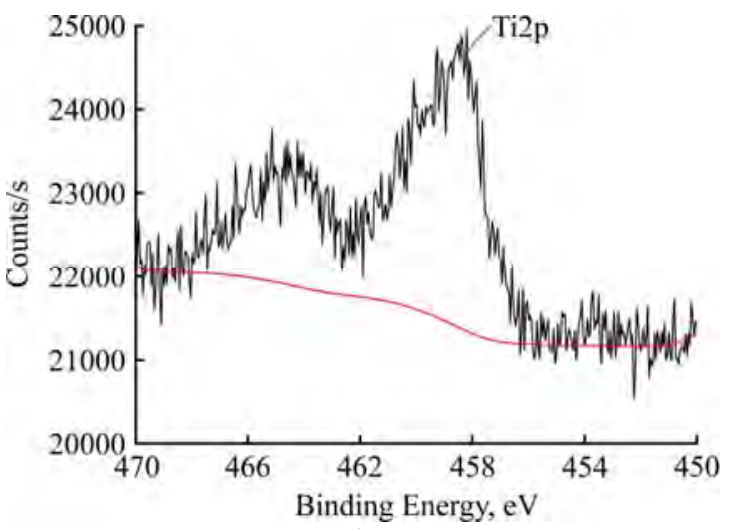

(b)

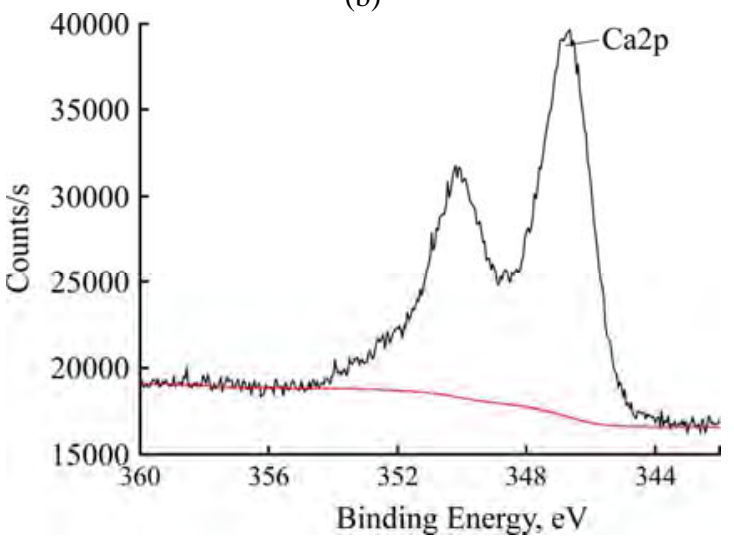

(d)

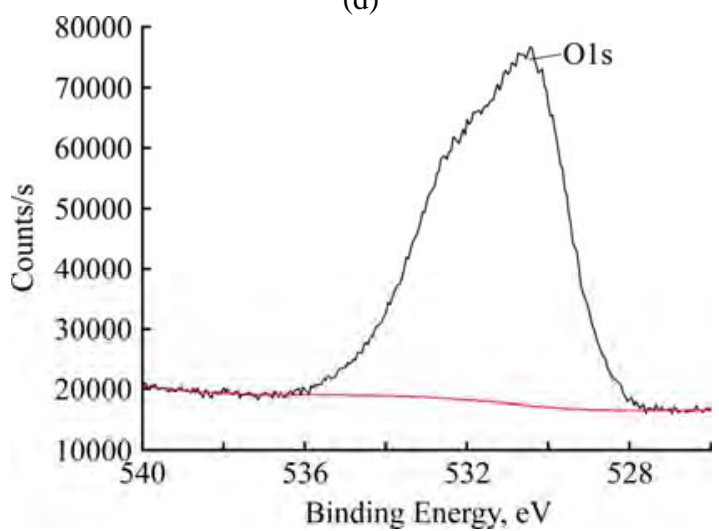

(f)

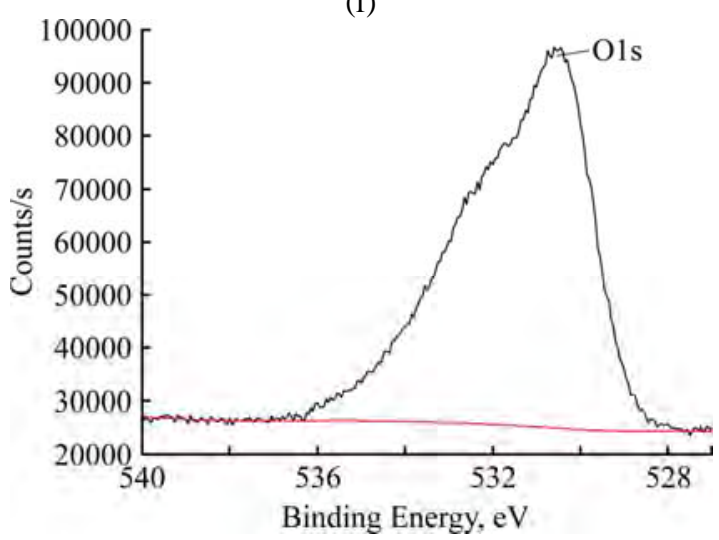

(h)

Fig. 6. XPS analysis of EDTA-2Na and EDTMPS MAO coatings.

related to the surface morphology as shown in Figure 7. When voltage reaches higher than around $150 \mathrm{~V}$ (nonfaradaic district), the formed thin oxidation insulating film starts to be broken down, and MAO process occurs simultaneously. According to the recent studies of discharge in liquid especially discharge plasma in lower temperature liquid, there are three simultaneous different processes of three typical areas taking place during MAO microcosmic processes as illustrated in Figure 7. 


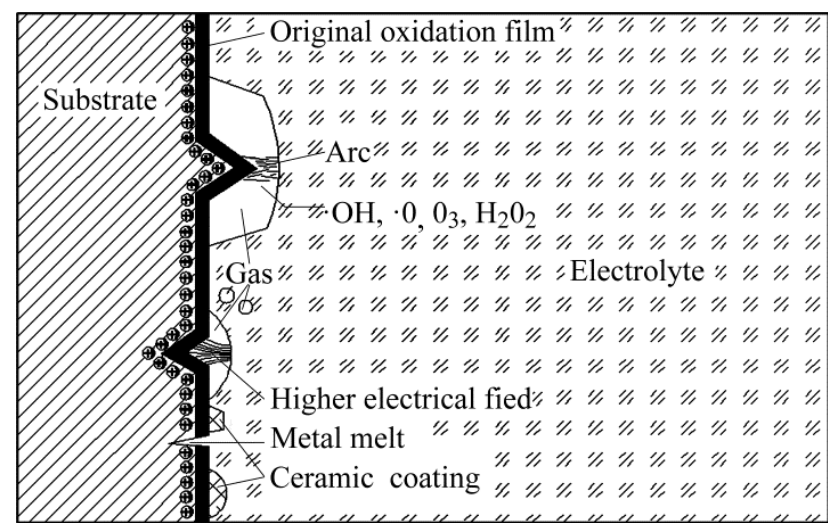

Fig. 7. Schematic of the surface process during MAO treatment.

The cusp area of Ti alloy sample surface is a similar needle-plane electrode system. The cusp is a needle. The gas-liquid interface is huge relatively so that it can be considered to be approximately straight as a plane. From the schematic diagram, it can be found that the cusp accumulates mass positive charges, when the sum voltage of accumulated charges and applied voltage reaches a certain value, discharges would arise. Sato, his co-researchers and others have studied the different discharges depending on the appearance and the spectrum between needle and plane [29-31]. When discharge reached the plane, it is common spark; before the arrival, it shows brilliant whitish spark. The appearance above exists in MAO process as H. Habazaki reported [32]. Most electrical energy turns into spark discharge including the two discharges above, and the energy expends through the formation and expandation of the discharge channels and the heat work exchange with the cusp area's surrounding electrolyte [2], [14] [32-33]. Thus, it can be concluded that during MAO process, the energy from the electrical power majorly turns into the consumption of mechanical work (exploration of the discharge channel) and heat work. The theories above could also explain the lower efficiency of energy utilization for phases formation and thickness growth of MAO coatings. On the other hand, the discharge also brings active particles, $\mathrm{O}_{2}$, free radical $\cdot \mathrm{OH}$, free radical $\mathrm{H}_{2} \mathrm{O}_{2}$, free radical $\cdot \mathrm{H}$ and others [29-32]. The reactions are as follows: heat

By the effects of electrical field and current Joule

$$
\begin{gathered}
\mathrm{H}_{2} \mathrm{O}+\text { heat } \rightarrow \mathrm{H}_{2} \mathrm{O}_{\text {gas }}, \\
2 \mathrm{H}_{2} \mathrm{O}+\text { electricity } \rightarrow 2 \mathrm{H}_{2 \text { gas }}+O_{\text {2gas }} .
\end{gathered}
$$

Breaking down and ionization

$$
\mathrm{H}_{2} \mathrm{O}_{\text {gas }}+e^{-*} \rightarrow \mathrm{H}_{2} \mathrm{O}^{+}+2 e^{-} \text {. }
$$

$\mathrm{H}_{2} \mathrm{O}^{+}$is accelerated by the electrical field to be charged panicle $\left(\mathrm{H}_{2} \mathrm{O}^{+*}\right)$

$$
\mathrm{H}_{2} \mathrm{O}^{+}+\text {cathode fall } \rightarrow \mathrm{H}_{2} \mathrm{O}^{+*} \text {. }
$$

$\mathrm{H}_{2} \mathrm{O}^{+*}$ reacts with liquid $\mathrm{H}_{2} \mathrm{O}$

$$
\begin{gathered}
\mathrm{H}_{2} \mathrm{O}^{+*}+n \mathrm{H}_{2} \mathrm{O} \rightarrow n \cdot \mathrm{OH}+n \cdot \mathrm{H}+\mathrm{H}_{2} \mathrm{O}^{+}, \\
\mathrm{H}_{2} \mathrm{O}^{+}+\mathrm{H}_{2} \mathrm{O} \rightarrow \cdot \mathrm{OH}+\mathrm{H}_{3} \mathrm{O}^{+}, \\
\cdot \mathrm{OH}+\cdot \mathrm{OH} \rightarrow \mathrm{H}_{2} \mathrm{O}_{2} ;
\end{gathered}
$$

*represents excited state and high-energy particle; $n$ is nonfaradaic constant.

$\cdot \mathrm{OH}, \mathrm{O}_{2}$ and $\mathrm{H}_{2} \mathrm{O}_{2}$ have higher oxidation ability to react with components from the electrolyte. The whole process is with releasing vast heat. The reaction space is limited (some paper reported the width of reaction space is about $5 \mu \mathrm{m}$ [33]). Therefore, the reactions above between active particles and electrolyte components are near the anode Ti alloy substrate surface, and the elements from the substrate are also involved in the reactions. Some papers also pointed out that the amount of - $\mathrm{OH}$ which has the highest oxidation ability near the anode is much more than that of cathode, and the speed of generation is faster. It also provides lateral illustration that the sample of cathode does not contain the components or elements from the electrolyte [21], [34-35]. Unfortunately, the studies of physical chemical process of solid-liquid and solid-gas interfaces during the discharge in liquid are rarely reported. In the experiments of this paper, $\mathrm{Ca}^{2+}$ and $\mathrm{P}^{-3}$ were introduced into the $\mathrm{TiO}_{2}$-based coating as a result of the process above. The strong oxidation ability of $\cdot \mathrm{OH}, \mathrm{O}_{2}$ and $\mathrm{H}_{2} \mathrm{O}_{2}$ can explain the phenomenon that $\mathrm{P}^{3-}$ exists in the coating. The free radicals react with $\mathrm{Ti}$ alloy, and finally $\mathrm{TiO}_{2}$-based coating is generated.

For the even area, a gas inelastic collision theory is established. As the voltage of MAO $(150 \mathrm{~V} \sim 700 \mathrm{~V})$ is lower compared with other liquid plasma processes, the amount of electron is lower as a result of the insufficient inelastic collision of gas molecule, which is due to low intensity electrical field. The inelastic collisions of gas molecules and other particles would arouse ionization. When the electron density brought by inelastic collision reaches a certain level, micro discharge channels would be formed between the substrate and the liquid. The requirement of this phenomena is pulse power which is also the typical power of MAO process. The energy during the whole process of the even area can be neglected compared with that of the cusp area. On the other hand, the micro reactions process of the two area types is splitting [32], which means new cusp areas are generated and reacts fast. Thus, the reaction of even area can be omitted during the whole MAO process.

Sunk area is with higher electrical field due to its special shape. The electron speed increases quickly and significantly beyond $5 \mathrm{eV}$ [21]. The accelerated electron experiences multiple elastic collisions with the consumption of energy and finally reaches an inelastic collision. It leads to ionization, segregation 
and plasma. Active oxide particles are produced, and the subsequent reactions are common with cusp area. The whole process is milliseconds [32], so that the heat during the process is not able to release. The reaction area's volume is micro. Thus, the whole process can be deemed an adiabatic process. According to thermodynamics:

Adiabatic process:

$$
\ln T+(\gamma-1) \ln V=\text { constant, }
$$

$T$, temperature; $\gamma$ - heat capacity ratio; $V$ - volume

$$
\begin{aligned}
V & =\frac{n R T}{P}, \\
P^{1-\gamma} T^{\gamma} & =\text { constant. }
\end{aligned}
$$

As the anode gas is not ideal gas:

$$
P^{1-n} T^{n}=\text { constant }
$$

$n$ is a constant, $\gamma>n>1$.

From the Eq. 4.11, it can be found that pressure increases with the declining of temperature. It is known that the temperature of the reaction area is significantly higher (maximum about 8000k [2], [13], [33]), and the temperature of surrounding electrolyte is about $300 \mathrm{k}$, which can be seen as a constant lower temperature source. The decreasing of $T$ is sharp in limited time. It is reported that $\mathrm{P}$ increa-ses heavily whose peak is even about $100 \sim 1000 \mathrm{MPa}$ of microscopic volume pressure [33]. Finally, the blast expansion of sharp increasing of pressure in micro space forms the "crater" shape porous surface structure. All the three processes of the different areas above are splitting. The cusp area, even area and sunk area are generated and coated repeatedly during the whole process. Finally, the coating is fabricated.

The elements of the electrolyte are introduced into the coating by diffusion, discharge plasma and various physical chemical effects. There exists the replacement of $\mathrm{Ti}$ or $\mathrm{O}$ ions by the elements $\mathrm{Ca}$ and $\mathrm{P}$ in the experiments of this paper, which results in the amorphous calcium phosphorus compound as analyzed by XRD and EDS. The properties of two electrolytes are different, and the two coatings show difference. Nonetheless, the differences between the MAO coating of EDTA-2Na and that of EDTMPS could be neglected. The properties (structure, morphologies and composition) of the two MAO coatings are similar generally. It is feasible and meaning that using EDTMPS to replace the current common complexing agent EDTA-2Na in Ca-P bioactive electrolyte.

\section{CONCLUSION}

A new MAO ceramic coating was fabricated in Ca-P electrolyte with a new complexing agent
EDTMPS instead of current common one EDTA-2Na. The compositions, structures and morphologies of the two different MAO coatings of EDTMPS and EDTA-2N are similar. The thicknesses are around $4 \sim 5 \mu \mathrm{m}$. The common phases are rutile $\mathrm{TiO}_{2}$, anatase $\mathrm{TiO}_{2}$, brookite $\mathrm{TiO}_{2}$, nonstoichiometric titanium oxide and $\mathrm{Ca}_{3} \mathrm{P}_{2}$. The MAO coating of EDTA-2Na contains $\mathrm{Ca}_{3}\left(\mathrm{PO}_{4}\right)_{2}$ which is not detected in that of EDTMPS. The surface morphology statistics, pores density(EDTMPS 2518.5/10-8m ${ }^{2}$ and EDTA-2Na 3625.8/10-8m ${ }^{2}$ ) and pores size parameters (EDTMPS 69.505 and EDTA-2Na 53.836), show difference. It is the product of the coating and condensation of more melting metal generated in EDTMPS electrolyte during the MAO process. The porosities are similar with about 22\%. The result of XPS analysis Ti2p indicates that the existence of non-stoichiometric titanium oxide can be attributed to replacement, vacancies and defects in $\mathrm{TiO}_{2}$-based original coating. The structure, composition and properties of EDTMPS MAO coating are similar with that of EDTA-2Na.

In MAO process, different areas reactions models are established and concluded according to the recent published papers of discharge plasma in lower temperature liquid and thermodynamics. The cusp area is a similar needle-plane electrode model where arc plays a major role. A gas inelastic collision theory is established for the even area where the inelastic diffusion between the electron and anode gas is kinetics source, and the area's influence could be ignored compared with the other two. The electrical field dominated the kinetics source in sunk area. Crater shapes on MAO ceramic coating are due to the huge pressure. Active particles, $\mathrm{O}_{2}$, free radical $\cdot \mathrm{OH}$, free radical $\mathrm{H}_{2} \mathrm{O}_{2}$, free radical $\cdot \mathrm{H}$ brought from discharge plasma play an important influence on the chemical reactions and physical transformations.

\section{REFERENCES}

1. Wu H.H., Lu X.Y., Long B.H. The Effects of Cathodic and Anodic Voltages on the Characteristics of Porous Nanocrystalline Titania Film Fabricated by Micro-arc Oxidation. Mater Lett. 2005, 59, 370-375.

2. Yerokhin A.L., Nie X., Leyland A. Plasma Electrolysis for Surface Engineering. Surf Coat Technol. 1999, 122, 73-93.

3. Anusavice K.J., Philips R.W., editors. Philips' science of dental materials. 11th ed. St Louis: EIsevier, 2003. P. 743-53.

4. Yuan-Hong Wang, Zhan-guo Liu, Jia-Hu Ouyang, et. al. Preparation and High Temperature Oxidation Resistance of Microarc Oxidation Ceramic Coatings Formed on $\mathrm{Ti}_{2} \mathrm{AlNb}$ Alloy. Appl Surf Sci. 2012, 258, 8946-8952. 
5. McKee D.W., Savage R.H., Gunnoe G. Chemical Factors in Carbon Brush Wear. Wear. 1972, 22, 193-214.

6. Krishna L. Rama, Somaraju K.R.C., Sundararajan G. The Tribological Performance of Ultra-hard Ceramic Composite Coatings Obtained Through Microarc Oxidation. Surf Coat Technol. 2003, 164, 484-490.

7. Yerokhin A.L., Leyland A., Matthews A. Kinetic Aspects of Aluminium Titanate Layer Formation on Titanium Alloys by Plasma Electrolytic Oxidation. Appl Surf Sci. 2002, 200, 172-184.

8. Wei Yang, Ai-ying Wang, Bai-ling Jiang. Corrosion Resistance of Composite Coating on Magnesium Alloy using Combined Microarc Oxidation and Inorganic Sealing. Transactions of Nonferrous Metals Society of China. 2012, 22, 760-763.

9. Lei Wen, Yaming Wang, Ying Jin, et al. A Metasilicate-based Ceramic Coating Formed on Magnesium Alloy by Microarc Oxidation and its Corrosion in Simulated Body. J Mater Sci Technol. 2013, 29(12), 1129-1133.

10. Chen Fei, Zhou Hai, Chen Chen, et al. Study on the Tribological Performance of Ceramic Coatings on Titanium Alloy Surfaces Obtained Through Microarc Oxidation. Prog Org Coat. 2009, 64(2-3), 264-267.

11. Lei Wen, Yaming Wang, Y. Zhou, et. al. Iron-rich Layer Introduced by SMAT and its Effect on Corrosion Resistance and Wear Behavior of $2024 \mathrm{Al}$ Alloy. Mater Chem Phys. 2011, 126, 301-309.

12. Zhou R., Wei DQ., Feng W., et al. Bioactive Coating with Hierarchical Double Porous Structure on Titanium Surface Formed by Two-step Microarc Oxidation Treatment. Surf Coat Technol. 2014, 252(8), 148-156.

13. Wei D.Q., Zhou Y., Jia D.C., Wang Y.M. Characteristic and in Vitro Bioactivity of Microarc Oxidized $\mathrm{TiO}_{2}$-Based Coating after Chemical Treatment. Acta Biomaterialia. 2007, 3, 817-827.

14. Hussein R.O., Nie X., Northwood D.O. An Investigation of Ceramic Coating Growth Mechanisms in Plasma Electrolytic Oxidation (PEO) Processing. Electrochim Acta. 2013, 113, 111-119.

15. Malyshev V.N., Zorin K.M. Features of Microarc Oxidation Coatings Formation Technology in Slurry Electrolytes. Appl Surf Sci. 2007, 254, 1511-1516.

16. Gao Yonghao, Yerokhin Aleksey, Parfenov Evgeny et. al. Application of Voltage Pulse Transient Analysis during Plasma Electrolytic Oxidation for Assessment of Characteristics and Corrosion Behaviour of Ca- and P-containing Coatings on Magnesium. Electrochim Acta. 2014, 149, 218-230.

17. Shahrouz Zamani Khalajabadi, Mohammed Rafiq Abdul Kadir, Sudin Izman, et. al. Effect of Mechanical Alloying on the Phase Evolution, Microstructure and Bio-corrosion Properties of a $\mathrm{Mg} / \mathrm{HA} / \mathrm{TiO}_{2} / \mathrm{MgO}$ Nanocomposite. Ceram Int. 2014, 40, 16743-16759.

18. Gu X.N., Li N., Zhou W.R., et. al. Corrosion Resistance and Surface Biocompatibility of a Microarc
Oxidation Coating on a Mg-Ca Alloy. Acta Biomaterialia. 2011, 7, 1880-1889.

19. Ho-Jun Song, Kyung-Ha Shin, Min-Suk Kook, et. al. Effects of the Electric Conditions of AC-type Microarc Oxidation and Hydrothermal Treatment Solution on the Characteristics of Hydroxyapatite Formed on Titanium. Surf Coat Technol. 2010, 204, 2273-2278.

20. Shi Changtao. The Improvement of the Synthesis Method of EDTMPS. Liaoning Chemical Industry. 2004, 33(4), 213-214.

21. Sun Bing. Discharge Plasma in Liquid and its Application. Beijing: Science Press, 2013. 251 p.

22. Cheng Su Y. Oral Implantology. Beijing: People's medical Publishing House, 2004. 431 p.

23. Gallagher T.J. Simple Dielectric Liquid. Oxford: Clarendon Press, 1975. 160 p.

24. Yong Yang, Young I. Cho., Alexander Fridman. Plasma Discharge in Liquid: Water Treatment and Applications. Florida: CRC Perss, 2012. P. 210.

25. Zastawny H.Z., Romat H., Karpel vel Leitner N., et. al. Pulsed Arc Discharges for Water Treatment and Disinfection. Electrostatics 2003: proceedings of the Electrostatics Conference of the Institute of Physics, Edinburgh, UK, 23-27 March, 2003, Bristol; Philadelphia : Institute of Physics conference series, 2004, vol. 137, 325-330.

26. Yamaguchi T., Chong S-H., Hirata F. Mode-coupling Analysis of the Translational and Rotational Diffusion of Polar Liquids; Acetonitrile and Water. J Mol Liq. 2004, 112(3), 117-124.

27. Ikonopisov S. Theory of Electrical Breakdown during Formation of Barrier Anodic Films. Electrochim Acta. 1977, 22(10), 1077-1082.

28. Albella J.M., Montero I., Martinez-Duart J.M. Electron Injection Sand Avalanche during the Anodic Oxidation of Tantalum. J Electrochem Soc. 1984, 131(5), 1101-1108.

29. Anto Tri Sugiarto, Masayuki Sato. Pulsed Plasma Processing of Organic Compounds in Aqueous Solution. Thin Solid Films. 2001, 386(2), 295-299.

30. Sun B., Sato M., Harano A., and Clements J.S. Pulsed Plasma Processing of Organic Compounds in Aqueous Solution. J Electrostat. 1998, 43(2), 115-126.

31. Saldin D.K., Shneerson V.L., Fung R. Surface Structure Solution by X-ray Diffraction: Structure Completion with Positivity and Atomicity Constraints. Physica B Condensed Matter. 2003, 336(1-2), 16-26.

32. Habazaki H., Tsunekawa S., Tsuji E., et. al. Formation and Characterization of Wear-resistant PEO Coatings Formed on $\beta$-titanium Alloy at Different Electrolyte Temperatures. Appl Surf Sci. 2012, 259, 711-718.

33. Wang H.B., Fang Z.G., Jiang B.L. Microarc Oxidation Technology and its Applications in Sea Environment. Beijing: National Defense Industry Press, 2010. 316 p.

34. Spinks J., Woods R.J. An Introduction to Radiation Chemistry. $3^{\text {rd }}$ ed. New York: Wiley, 1976. 520 p. 
35. Joshi A.A., Locke B.R., Arce P., and Finney W.C. Formation of Hydroxyl Radicals, Hydrogen Peroxide and Aqueous Electrons by Pulsed Streamer Corona Discharge in Aqueous Solution. J Hazard Mater. 1995, 41(1), 3-30.

Received 05.01.15 Accepted 14.04.15

\section{Реферат}

Получено новое МДО керамическое покрытие в Са-Р электролите с экологичным, легко распадающимся комплексным агентом EDTMPS взамен обычно используемым EDTA-2Na. Трехмерный оптический и сканирующий электронный микроскопы использовались для изучения морфологии поверхности и поперечного сечения покрытия с применением программы ImageJx 2.0. Элементный и фазовый состав определялся с помощью EDS и XRD анализов соответственно. XPS метод позволил понять и предоставил больше информации о компонентах двух комплексных составляющих МДО - покрытий. Результаты указывают, что элементы и фазы композиций двух МДО керамических покрытий подобны. Морфологии поверхностей различны, что является результатом большего подплавления металла в течение обработки в EDTMPS по сравнению с EDTA-2Na. Результаты недавних исследований разряда и плазменного разряда в низкотемпературной жидкости, а также термодинамика процессов были введены для предложения моделей МДО процессов, которые разделяются на три части: острую, пологую и затухающую области. В фазовых трансформациях значительную роль играют активные частицы $\mathrm{O}_{2}$, свободные радикалы $\cdot \mathrm{OH}$, свободные радикалы $\mathrm{H}_{2} \mathrm{O}_{2}$, свободный радикал $\cdot \mathrm{H}$, поставляемые разрядом и плазменным разрядом, элементы электролита, диффундирующие из электролита к покрытию и подложке, и химические реакции. Форма кратера на поверхности обусловлена главным образом возрастанием давления с уменьшением температуры. Интерпретация МДО процессов на базе термодинамической теории и плазменного разряда низкотемпературной жидкости была развита.

Ключевые слова: микродуговое оксидирование, сплавы титана, комплексный агент, плазменный разряд в низкотемпературной жидкости. 